\title{
An investigation of the gate control theory of pain using the experimental pain stimulus of potassium iontophoresis
}

\author{
STEVEN A. HUMPHRIES, MALCOLM H. JOHNSON, and NIGEL R. LONG \\ Massey University, Palmerston North, New Zealand
}

\begin{abstract}
This study investigated a prediction derived from gate control theory-that there would be a pulse of pain as a pain stimulus was being ramped off due to the rapidly transmitting, inhibitory large fiber activity falling away sooner at the spinal level than the excitatory activity of the slow-transmitting, small nociceptive afferents. A further prediction was that the more distant the peripheral stimulus was from the spine, the greater the pain pulse would be. Fourteen subjects had the pain stimulus of iontophoretically applied potassium ions $\left(\mathrm{K}^{+}\right)$applied to an upper and a lower site on the dominant arm. In a threshold detection task using the double random staircase method, subjects were asked to indicate whether they could detect a pulse of additional pain during this ramp-off phase. The average rate of stimulus ramp-off in order to detect a pain pulse was statistically greater for the upper-arm site $\left(14.3 \mu \mathrm{g} \mathrm{K}^{+} / \mathrm{sec}\right)$ than for the lower-arm site $\left(9.4 \mu \mathrm{g} \mathrm{K}^{+} / \mathrm{sec}\right)$. These results were consistent with gate control theory. Alternative explanations, including intrinsic differences in nociceptive responding for different dermatomes and anode break, were considered. It was concluded that the detection of a pain pulse during the ramping off of a peripheral pain stimulus potentially provides a quantitative measure of the spinal modulation of pain.
\end{abstract}

The gate control theory of pain (Melzack \& Wall, 1965, 1988) has been said to be "an excellent first approximation of the neural interactions underlying the transmission of nociceptive information" (Price, 1988, p. 221). The major proposal of the gate control theory of pain is that the flow of nociceptive nerve impulses from the peripheral nerve system to the central nervous system is modulated in the dorsal horns of the spinal column (for a recent review, see Besson \& Chaouch, 1987). This neural mechanism is considered to act as a pain gate in which nociceptive transmission may be facilitated or inhibited at the spinal level.

According to the original gate control proposal (Melzack \& Wall, 1965), the first central transmission (T) cells in the substantia gelatinosa (SG) of the spinal dorsal horns are part of a set of fibers that made up the spinothalamic "pain" pathway. If the T-cells are sufficiently activated, pain might be experienced. That is, if the ascending output from the T-cells exceeds a critical level, the "pain action system" is activated.

The activity of the T-cells is dependent, at least partly, on the relative activity of the large-diameter low-threshold mechanoreceptive (A-beta) and small-diameter (A-delta and C) primary afferents. The large-diameter and smalldiameter afferents project not only to the T-cells, but also to interneurons which exert an inhibitory effect on the ter-

This research was supported by a Vice-Chancellor's Post Graduate Scholarship provided by Massey University to S.A.H. Correspondence should be addressed to S. A. Humphries, Department of Psychology, Massey University, Palmerston North, New Zealand (e-mail: s.a.humphries (a) massey.ac.nz). minals of both the large and small afferents where they synapse with the T-cells (Figure 1). Inhibition is enhanced by large-fiber activity and reduced by small-fiber activity (Melzack \& Wall, 1965, 1988). Melzack and Wall (1988) also hypothesized that there are descending central controls, which can modulate nociceptive transmission at the spinal level. That is, central processes could also open and close the spinal pain gate.

In summary, the extent to which we perceive pain depends, at least in part, on the ratio of the large- and smalldiameter peripheral afferent activity. Small-diameter activity, associated with nociception, tends to increase T-cell activity (open the pain gate). Large-diameter activity, associated with non-noxious mechanical sensation, tends to reduce T-cell activity (close the pain gate). Consequently, the transmission of peripheral nociceptive inputs can be modulated by non-nociceptive peripheral inputs. In addition, the transmission of peripheral nociceptive messages is believed to be under central supraspinal control. Thus their model formally includes central and psychological factors as an integral part of pain processing.

Subsequent studies have produced neurophysiological evidence in support of gate control theory (e.g., Pohl et al., 1992; Steedman, Molony, \& Iggo, 1985). However, the neuroanatomy and neurophysiology of spinal nociceptive modulation is obviously more complicated than that de. picted in Melzack and Wall's original model. Recent mod els depicting the morphological-functional relationship of the dorsal horns (e.g., Coderre, Katz, Vaccarino, 8 Melzack, 1993; Fields, Heinricher, \& Mason, 1991) serv to emphasize the simplification embodied in Melzack an Wall's original gate control theory. 


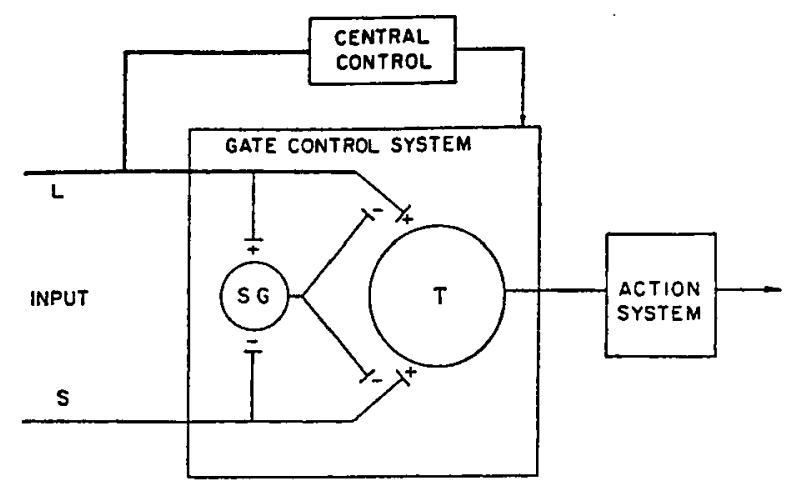

Figure 1. Schematic diagram of the gate control theory of pain, as proposed by Melzack and Wall (1965). SG, substantia gelatinosa; $T$, transmission cell; $L$, large-diameter fast afferents; $S$, small-diameter slow afferents. - , inhibitory; + , facilitatory. From "Pain Mechanisms: A New Theory," by R. Melzack and P. D. Wall, 1965, Science, 150, p. 975. Copyright 1965 by American Association for the Advancement of Science. Adapted with permission.

Nevertheless, while there is criticism of gate control theory (Liebeskind \& Paul, 1977; Nathan, 1976; Willis \& Coggeshall, 1978), the segmental spinal inhibition of nociceptive peripheral afferents by large-diameter nonnociceptive afferents has been extensively studied and repeatedly confirmed (Handwerker, Iggo, \& Zimmermann, 1975; Price \& Wagman, 1970; Salter \& Henry, 1987).

The known time course of spinal neural mechanisms suggests that relatively rapid changes in large-diameter peripheral input may be able to modulate the transmission of noxious stimuli. Wall (1988) has described the time course of gate control action due to peripheral inputs at the first synapse to be in the order of milliseconds to seconds, as opposed to slower mechanisms, such as descending controls, that act over minutes or hours.

Experimental studies, using spinalized or decerebrate animals, investigating the inhibition of transmission of nociceptive stimulation at the spinal level by activity in largediameter peripheral afferents clearly indicate that the modulation effects are potentially rapid, typically taking less than $70 \mathrm{msec}$ from the start of innocuous cutaneous vibration with a rapid return to baseline following cessation of the conditioning stimuli (e. g., Dickenson, Oliveras, \& Besson, 1979; Salter \& Henry, 1986, 1987; Woolf \& Wall, 1982).

Higher centers of the central nervous system can also modulate nociceptive sensory function at the spinal level. Accordingly, to understand the process of spinal gating, account must be taken of supraspinal influences (for reviews, see Besson \& Chaouch, 1987; Willis, 1988). A number of investigators have suggested that somatosensory stimuli might activate supraspinal control (Fields \& Basbaum, 1978). Certainly supraspinal sites involved in descending control receive large-diameter somatosensory inputs (Murphy \& Behbehani, 1993; Roberts, Eaton, \& Salt, 1992).

The clinical and experimental findings for the action of high-frequency low-intensity TENS (Basbaum \& Fields,
1984; Garrison \& Foreman, 1994), vibration (Guieu, Tardy-Gevert, \& Giraud, 1992), and dorsal column stimulation (Handwerker et al., 1975) all demonstrate that supraspinal action has a somewhat delayed onset of maximal effectiveness, and prolonged effects beyond the termination of the conditioning stimulus (Lindblom, Tapper, \& Wiesenfeld, 1977).

It is reasonable, therefore, to investigate the possibility that modulatory changes in nociceptive transmission at the spinal level due to relatively rapid changes in large-diameter afferent input are measurable in terms of changes in perceived pain levels. An assumption with such an investigation is that no supraspinal mechanism will rapidly override the large-diameter afferent modulation of nociceptive transmission at the spinal level when the time course of such spinal changes is in the order of a few hundred milliseconds.

The present study represents an attempt to assess pain perception as a function of changes in the relative activity of large- and small-diameter nociceptive afferents. The ability to measure the effects of such changes would permit a quantitative investigation of one of the main tenets of gate control theory-that nociceptive transmission is a function of the balance between large-diameter non-nociceptive peripheral inputs and small-diameter nociceptive peripheral inputs. The different conduction velocities of these peripheral afferents can be utilized to produce differential levels of neural activity at the spinal level in the two afferent types.

\section{The Ramp-Off Model}

A constant peripheral stimulus that activated both large-diameter and small-diameter peripheral afferents would be perceived as painful, but, according to the gate control theory, there would be some reduction in the intensity of the pain due to the inhibitory action of the largefiber activity at the spinal level.

If the peripheral stimulus was then removed-that is, ramped off over a period of a few hundred millisecondsthen the large-diameter afferent (A-beta) activity at the spinal level would rapidly cease, because of the relatively rapid transmission of neural impulses along those fast conducting afferents. However, activity in the small-diameter afferents (A-delta and especially C-fibers) at the spinal level would remain temporarily at the original levels, owing to their relatively slow neural conductance. Consequently, for a brief period of time, while the absolute level of nociceptive neural input at the spinal level would remain unchanged, the inhibitory action of the large-diameter fast-conducting afferents would be absent, allowing an increase in spinal nociceptive transmission which might then be perceived as a transient increase in pain above that of the background level that is, a pulse of pain would be detected. This pulse of pain would then be followed by a decrease in pain, dropping away to no pain, as the nociceptive peripheral input eventually also dropped to zero at the spinal level. The faster the pain stimulus was ramped off, the greater the activity differential between the fast and slow conducting afferents at the spinal level, and consequently the greater the pain pulse. 


\section{Conduction Velocities in Peripheral Afferents}

The thinly myelinated A-delta afferents have conduction velocities in humans of between 5 and $28 \mathrm{~m} / \mathrm{sec}$ (Adriaensen, Gybels, Handwerker, \& Van Hees, 1983). For example, using microneurographic techniques, mean A-delta conduction velocities in humans have been reported at $19.2 \mathrm{~m} / \mathrm{sec}(S D= \pm 7.2)$ (Adriaensen et al., 1983). This is consistent with other human studies (Van Hees, 1976), and with animal studies that have typically found conduction velocities from 2 to $30 \mathrm{~m} / \mathrm{sec}$ for the A-delta group (e.g., Brown \& Iggo, 1967; Perl, 1968).

The unmyelinated afferent $\mathrm{C}$-fibers in humans mainly have conduction velocities of between 0.5 and $2 \mathrm{~m} / \mathrm{sec}$ (Torebjörk, 1974; Torebjörk \& Hallin, 1974, 1976; Van Hees \& Gybels, 1972, 1981). Afferents with conduction velocities less than $2.5 \mathrm{~m} / \mathrm{sec}$ are considered to belong to the mammalian C-fiber group (Douglas \& Ritchie, 1962; Gasser, 1950).

The myelinated A-beta afferents have neural conduction velocities predominantly around $50 \mathrm{~m} / \mathrm{sec}$ (Treede, Jahnke, \& Bromm, 1984). Fields (1990) has reported the conduction velocities of A-beta fibers to be $33-75 \mathrm{~m} / \mathrm{sec}$, with C polymodal afferents being $0.5-2 \mathrm{~m} / \mathrm{sec}$, and A-delta afferents being $5-30 \mathrm{~m} / \mathrm{sec}$. For the purposes of calculation in the present study, typical average neural conduction velocities are taken to be $1 \mathrm{~m} / \mathrm{sec}$ for C-fibers, $15 \mathrm{~m} / \mathrm{sec}$ for A-delta fibers, and $50 \mathrm{~m} / \mathrm{sec}$ for A-beta fibers.

\section{Iontophoretic Pain Stimulus}

Potassium iontophoresis was selected as the experimental pain stimulus, because the results of a previous study (Humphries, Long, \& Johnson, 1994) and other prior research indicate that it possesses a number of characteristics that make it a uniquely suitable pain stimulus for investigating the neural modulation of pain as proposed by gate control theory.

First, potassium iontophoresis can deliver a precise magnitude of nociceptive stimulation, and the intensity of the stimulus can be rapidly changed. Second, potassium iontophoresis produces stimulation of both large- and smalldiameter afferents. It has been determined that locally applied $\mathrm{K}^{+}$can activate $\mathrm{C}$ polymodal nociceptors (Bessou \& Perl, 1969; Kumazawa \& Perl, 1977), as well as A-delta and A-beta fibers (Kumazawa \& Mizumura, 1977; Monnier, 1975; Uchida \& Murao, 1974). Owing to their lack of myelin sheath and small diameter, the C-fibers have been found to be particularly sensitive to the chemical influences of $\mathrm{K}^{+}$in the immediate extracellular environment (Guilbaud, 1988; Monnier, 1975).

Finally, potassium iontophoresis produces relatively little inflammation, so the effects of peripheral neural stimulation can be investigated in the relative absence of these reactions. This probably contributes to the fact that, even with repeated trials, the stimulus can be ramped off quickly with no apparent aftereffects, such as lingering residual pain.

\section{Predictions of the Ramp-Off Model}

The effects of ramping off the peripheral potassium stimulus in terms of the stimulation at the spinal level can be depicted in graphical form. Figure 2A shows the rate of peripherally applied $\mathrm{K}^{+}$"seen" at the spinal level for largediameter, fast, A-beta afferents and the smaller-diameter, slower, A-delta and C-fiber afferents, for a peripheral stimulation site on the subject's arm $60 \mathrm{~cm}$ from the spine. The ramp off of the applied stimulus starts at $100 \mathrm{msec}$ and is ramped down to zero at a constant rate over $300 \mathrm{msec}$. Given the nominated typical average conduction velocities of $50 \mathrm{~m} / \mathrm{sec}$ for A-beta fibers, $15 \mathrm{~m} / \mathrm{sec}$ for A-delta fibers, and $1 \mathrm{~m} / \mathrm{sec}$ for C-fibers, the peripherally applied $\mathrm{K}^{+}$ "seen" at the spinal level would start to fall at $112 \mathrm{msec}$ in the A-beta fibers, at $140 \mathrm{msec}$ in the A-delta fibers, and not until $700 \mathrm{msec}$ in the $C$ fibers. The peripherally applied $\mathrm{K}^{+}$"seen" at the spinal level would drop to zero by $412 \mathrm{msec}, 440 \mathrm{msec}$, and $1,000 \mathrm{msec}$ for the A-beta, A-delta, and $\mathrm{C}$ fibers, respectively.

During the time period from $112 \mathrm{msec}$ to $700 \mathrm{msec}$ the $C$-fiber activity at the spinal level would remain unchanged, while the fall-off in A-beta activity would, in accordance with the gate control model, allow increased nociceptive transmission at the spinal level. This increase in nociceptive spinal transmission should be associated with a concomitant pulse of pain.

A further prediction of the gate control model is that the closer the distance the peripheral stimulus is to the spine, the smaller the pulse of pain will be, because the temporal separation between a neural signal carried by the largediameter fast-conducting afferents and the slower smalldiameter afferents will decrease with decreased peripheral distance traveled. Figure 2B shows the rate of peripherally applied $\mathrm{K}^{+}$"seen" at the spinal level for large-diameter, fast, A-beta afferents and the smaller-diameter, slower, A-delta and C-fiber afferents, for a peripheral stimulation site on the subject's arm only $30 \mathrm{~cm}$ from the spine. The ramp off of the applied stimulus starts at $100 \mathrm{msec}$, and is ramped down to zero at a constant rate over $300 \mathrm{msec}$, the same rate as for the applied stimulus site $60 \mathrm{~cm}$ from the spine. In this case, the peripherally applied $\mathrm{K}^{+}$"seen" at the spinal level would start to fall in half the time as for the $60-\mathrm{cm}$ condition - that is, at $106 \mathrm{msec}$ in the A-beta fibers, at $120 \mathrm{msec}$ in the A-delta fibers, and at $400 \mathrm{msec}$ in the $\mathrm{C}$ fibers. The peripherally applied $\mathrm{K}^{+}$"seen" at the spinal level would drop to zero by 406, 420 , and $700 \mathrm{msec}$ for the A-beta, A-delta, and C fibers, respectively. The differential levels of $\mathrm{K}^{+}$between the A-beta fibers and the $\mathrm{C}$-fibers "seen" at the spinal level is much less in the $30-\mathrm{cm}$ condition (Figure 2B) than in the 60-cm condition (Figure 2A). Accordingly, the increase in nociceptive spinal transmission, and concomitant transient pulse of pain, should be much less in the $30-\mathrm{cm}$ condition than in the $60-\mathrm{cm}$ condition for the same peripheral noxious stimulus being ramped off.

The ramp-off model predicts that steeper ramp-off rates may be required at stimulation sites closer to the spine in order to produce a pulse of pain. For instance, if the rampoff time of the applied $\mathrm{K}^{+}$stimulus at the $30-\mathrm{cm}$ site is decreased from $300 \mathrm{msec}$ (Figure 2B) to $100 \mathrm{msec}$ (Figure 3), the $\mathrm{K}^{+}$differential seen at the spinal level for the $\mathrm{C}$-fibers compared with the A-beta fibers will substantially in- 

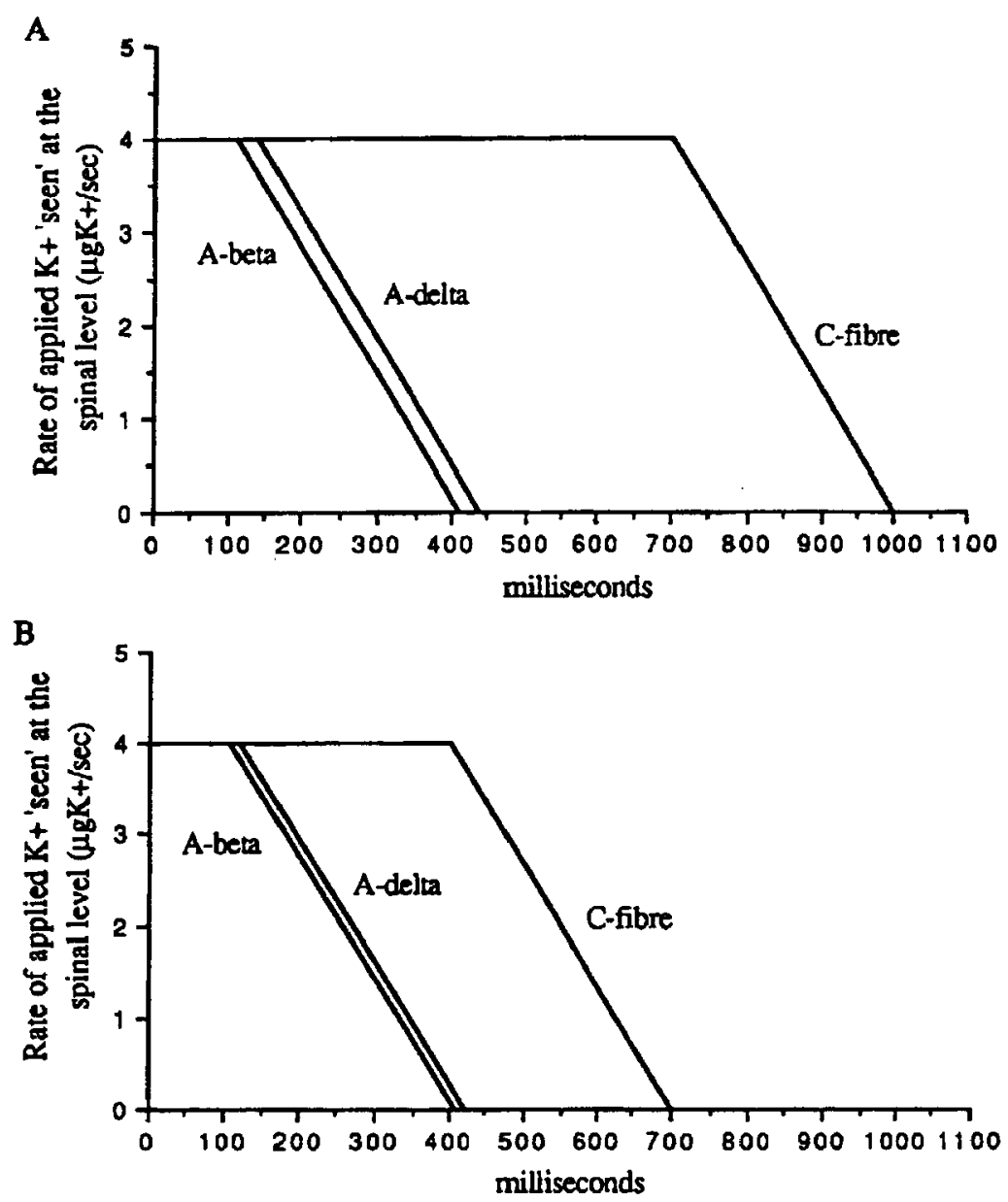

Figure 2. The rate of applied $\mathrm{K}^{+}$"seen" at the spinal level for large-diameter, fast, A-beta afferents and the smaller-diameter, slower, A-delta and C-fiber afferents, for a peripheral stimulation site on the subject's arm $60 \mathrm{~cm}$ from the spine $(A)$ and $30 \mathrm{~cm}$ from the spine (B). The $\mathrm{K}^{+}$stimulus is ramped to zero over $300 \mathrm{msec}$ in both $\mathrm{A}$ and $\mathrm{B}$. In the $60-\mathrm{cm}$ condition, there is greater differential for $\mathrm{K}^{+}$seen at the spinal level for the C-fibers than for the A-beta fibers, and this differential extends over a longer period of time.

crease during the ramp-off phase. When the ramp-off time is shortened to $100 \mathrm{msec}$, then for nearly $300 \mathrm{msec}$ the $\mathrm{K}^{+}$ seen at the spinal level for $\mathrm{C}$-fibers remains unchanged while the $\mathrm{K}^{+}$seen at the spinal level for the A-beta fibers is at zero (Figure 3). This difference in the $\mathrm{K}^{+}$seen at the spinal level for the A-beta and C-fibers persists for over $250 \mathrm{msec}$. This contrasts with the condition where the ramp-off time is $300 \mathrm{msec}$ (Figure 2B), in which the inhibitory effects of the A-beta afferents continues until after the $\mathrm{C}$-fiber activity has started to decrease.

On the basis of the ramp-off model of Humphries, Johnson, and Long (1993), Britton, Chaplain, and Skevington (1995) mathematically modeled T-cell activity during the ramp-off phase of the potassium iontophoresis pain stimulus, as proposed for the present experiment. Their results for simulated T-cell output in response to the ramping off of the pain stimulus agree that a pulse of pain should be generated (see Figure 4). As the simulation model shows, activity in the simulated T-cell is observed to transiently increase before decreasing during the ramping-off phase of the peripheral pain stimulus. If this increase in T-cell activity exceeded a critical level, an increase in pain should be perceptible.

In order for the predictions of the ramp-off model to be valid, a number of assumptions are made concerning the ramping-off of the potassium iontophoretic pain stimulus. First, it is assumed that the neural activity of the primary afferents tracks reasonably well that of the rate of the applied $\mathrm{K}^{+}$stimulus. That is, that the levels of $\mathrm{K}^{+}$"seen" at the spinal level, as depicted in Figures 2 and 3, are in fact a reasonable approximation of the neural activity in the respective afferent fibers. Our earlier experiments (Humphries et al., 1994) have shown that, for the levels of applied $\mathrm{K}^{+}$ used in the present experiment, there is a good linear relationship between the applied stimulus levels of $\mathrm{K}^{+}$and the resultant perceived pain. In addition, following removal of the applied stimulus, there is a rapid return to baseline levels of no perceived pain, even for pain tolerance trials 


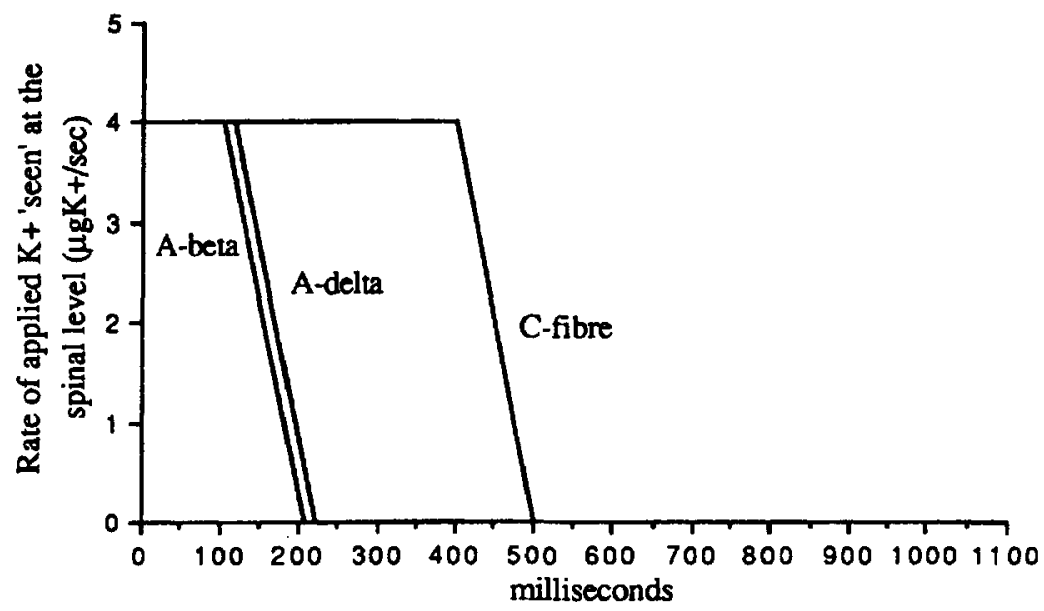

Figure 3. The rate of applied $\mathrm{K}^{+}$"seen" at the spinal level for large-diameter, fast, A-beta afferents and the smaller-diameter, slower, $A$-delta and $C$-fiber afferents, for a peripheral stimulation site $30 \mathrm{~cm}$ from the spine. The $\mathrm{K}^{+}$stimulus is ramped to zero over 100 msec. The $K^{+}$differential seen at the spinal level for the $C$-fibers compared with the A-beta fibers substantially increases during the ramp-off phase when the ramp-off time is reduced from 300 msec (Figure $2 B$ ) to $100 \mathrm{msec}$.

(Douglas, 1994). This indicates that, even with relatively high extracellular levels of $\mathrm{K}^{+}$, following removal of the stimulus there is a rapid clearance of the $\mathrm{K}^{+}$.

In addition, it is not necessary that the relationship between the rate of applied stimulus and the resultant neural activity be strictly linear. Indeed, any monotonic stimulusactivity relationship, for both the large-diameter and smalldiameter afferents, is sufficient to produce the effects predicted by the ramping-off model.

Second, the relative activity of each fiber type during the constant stimulus phase is not critical, and the predictions of the model are met, provided that the A-beta and C-fiber afferents are both stimulated at least to a moderate degree.

Third, the rapid fall-off in A-delta activity, leading to lower nociceptive transmission associated with these fibers, might cancel the effects of increased nociceptive transmission during the ramp-off phase, when it is predicted that there is decreased A-beta inhibition of the C-fibers. The nociceptive stimulus must therefore preferentially stimulate $\mathrm{C}$-fibers so that the pain experienced is predominantly C-fiber based. Iontophoretically applied $\mathrm{K}^{+}$would seem to be ideally suited to this requirement, since unmyelinated $\mathrm{C}$-fibers are especially sensitive to chemical stimulation, including $\mathrm{K}^{+}$depolarization (Guilbaud, 1988; Monnier, 1975), and this preferential C-fiber activation is consistent with the frequent report of burning pain with $\mathrm{K}^{+}$iontophoresis (Humphries et al., 1994; Ong, Singer, \& Wallace, 1980; Voudouris, Peck, \& Coleman, 1985). Cutaneous C-fiber nociceptors are also known to occur in greater density than cutaneous A-delta nociceptors, and unmyelinated fibers outnumber myelinated fibers approximately 4 to 1 (Burgess \& Perl, 1973; Iggo, 1974)which may add to preferential nociceptive transmission by $\mathrm{C}$ fibers with the cutaneous stimulation of $\mathrm{K}^{+}$iontophoresis.
Finally, lack of differential activity between A-delta and A-beta fibers (see Figure 2) indicates that the removal of inhibition by the A-beta fibers from the A-delta fiber activity will not produce a pulse of pain. That is, a single pulse of pain will be generated, arising from the differential activity between A-beta and C-fibers.

Other changes in nociceptive neural processing also have to be considered before accepting the predictions of the ramp-off model. Peripheral nociceptive stimulation is capable of inducing a number of peripheral and central nervous system changes. These changes include receptor sensitization (Bessou \& Perl, 1969; Campbell \& Meyer, 1983;

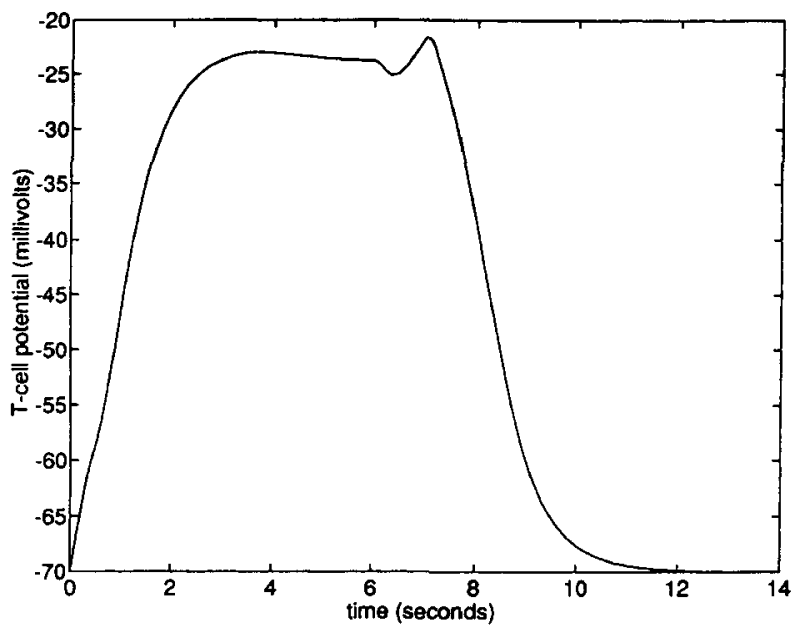

Figure 4. Mathematically modeled T-cell activity in response to the simulated ramping off of a peripheral potassium iontophoretic pain stimulus. From "A Mathematical Model for Pain: The Role of NMDA Receptors," by N. F. Britton, M. A. J. Chaplain, and S. M. Skevington. Manuscript submitted for publication. Adapted with permission. 
Koltzenburg, Kress, \& Reeh, 1992); peripheral nociceptor after-discharge (Beitel \& Dubner, 1976); sensitization of nociceptive spinal cord dorsal horn neurons (Perl, Kumazawa, Lynn, \& Kenins, 1976); and the wind-up of wide dynamic range neurons (WDR) by C-fibers (Mendell, 1966). However, in terms of the ramp-off model it would be expected that the rapid-acting ramp-off effects would be superimposed on top of any sustained changes in nociceptive processing that might also be present.

The objective of the present experiment was to establish a constant peripheral pain stimulus using iontophoretic administration of potassium and then ramp that stimulus off to see whether a pain pulse could be produced during the ramp-off phase. In accordance with the gate control theory of pain, it was predicted that a peripheral stimulus site closer to the spine would require a greater ramp-off rate in order to produce a detectable pain pulse.

\section{METHOD}

\section{Subjects \\ The subjects were 14 volunteer students, with ages ranging from 20 to 30 years. Prior to participation, all subjects completed a consent form that outlined the general nature of the experiment. They also completed a health check-list to determine whether any contraindicat- ing medical conditions were present. They were paid $\$ 15$ per session and were free to terminate participation at any stage of the study.}

\section{Apparatus}

The iontophoretic pain generator consisted of a computer-controlled constant-current power source designed to deliver a selected amount of current ranging from 0 to $25 \mathrm{~mA}$. Intensity levels could be selected in $0.1-\mathrm{mA}$ steps. The amount of $\mathrm{K}^{+}$delivered is directly proportional to the applied current, with $1 \mathrm{~mA} / \mathrm{sec}$ of current delivering $0.405 \mu \mathrm{g}$ of $\mathrm{K}^{+}$.

The electrodes that were attached to the subject's arm were similar to those described by Benjamin and Helvey (1963), Voudouris et al. (1985), and the same as used by Humphries et al. (1994). The anode consisted of a silver plate suspended in a plastic bowl with no base. This bowl was placed against the volar surface of the subject's arm. The subject's skin acted as the base for the bowl. This arrangement allowed a potassium chloride gel $(3 \% \mathrm{w} / \mathrm{v}$ potassium chloride; $1.0 \% \mathrm{w} / \mathrm{v}$ biological grade agar) in the bowl to be in direct contact with the subject's skin. The contact surface area of the gel was $12.5 \mathrm{~cm}^{2}$. The use of the potassium chloride solution in gel form prevented the solution's leaking from the electrode bowl, permitting the anode to be attached to the subject's arm without the need for excessive pressure to seal the base of the anodal bowl against the skin of the subject.

The cathode consisted of a silver plate $(4 \times 13 \mathrm{~cm})$ covered with several layers of saline-saturated medical gauze $(4 \% \mathrm{w} / \mathrm{v}$ sodium chloride) placed against the dorsal surface of the subject's arm. The medical gauze prevented direct skin contact with the cathodal silver plate, thereby avoiding any possibility of electrical skin burns.

\section{Procedure}

A standard protocol was adhered to for all sessions. Subjects were tested at the same time each day and were seated at a table with a dual set of stimulus electrodes attached to the dominant arm. The lower potassium anode provided a pain stimulus to the volar surface of the arm approximately $8 \mathrm{~cm}$ from the wrist. The upper potassium anode was placed on the subject's bicep. The average distance from the lower-arm site to the spine was $63.4 \mathrm{~cm}(S D=4.4)$, and for the upper-arm site, $33.6 \mathrm{~cm}(S D=1.6)$.
For each anode, a cathode was placed on the opposing surface of the arm. Prior to applying the electrodes, the palmar and volar surfaces of the subject's arm were prepared by light scrubbing with warm soapy water followed by an acetone $/ 90 \%$ alcohol solution $(1: 10 \mathrm{v} / \mathrm{v})$.

The subject's arm rested on a cushioned support throughout the experiment. A cutoff switch was positioned by the subject's nondominant hand, with which the subject could terminate any of the stimulus administrations immediately. The cutoff switch was not used during the experiment.

A familiarization session the day before the first experimental session was provided in order to give the subjects an opportunity to learn the nature of the tasks and to become familiar with using a visual analog scale (VAS), and to reduce possible anxiety. Immediately prior to each experimental session, the subjects were administered some stimulus trials. Along with the preparatory cleaning of the subject's arm, this helped to lower and stabilize electrode resistance (Tursky, 1974). It also refamiliarized the subjects with the experimental stimuli and the response procedures. Skin resistance was measured prior to the start of the main session. For most subjects, resistance was $5 \mathrm{k} \Omega$ or less prior to the start of each session.

The stimulus trials in a session alternated between the upper and lower anode sites with an interstimulus interval (ISI) of $10 \mathrm{sec}$ for each stimulus presentation. That is, each stimulus site had an ISI of $20 \mathrm{sec}$. A trial consisted of a warning beep on the computer followed by a lsec ramp-up to a preselected pain intensity level that was maintained for $4 \mathrm{sec}$. At the commencement of the experimental session, the stimulus levels were adjusted for each subject so that the perceived pain levels recorded on the VAS for the upper and lower stimulus sites were the same and were reported to be mildly to moderately painful

Subjects were told that at the end of the 4-sec period of constant pain either the pain would be ramped off smoothly or there would be a brief pulse of additional pain stimuli before the ramp-off. They were not told that the ramp-off rate would be varied. In fact, only the rate at which the stimulus was ramped off was varied; no pulse of additional pain stimulus was administered on any trial. The subjects were asked to indicate, by immediately removing their nondominant hand from a microswitch positioned on the table in front of them, any pain pulse that they detected. Threshold-detection reaction times were from the onset of the stimulus ramp-off until the microswitch was released. Timing was accurate to within $4 \mathrm{msec}$, and all reaction times were automatically recorded by computer.

For both the upper and lower stimulus sites the double random staircase method described by Cornsweet (1962), Gracely (1988), and Gracely, Lota, Walter, and Dubner (1988) was used to adjust the rate of stimulus ramp-off to determine the threshold of detection of the pain pulse-that is, to determine the slowest ramp-off rate that would still produce a perceptible pain pulse.

The double random staircase is not only efficient but also reported to be relatively free from subject bias (Cornsweet, 1962; Gracely, 1988). For each subject, the initial ramp-off rates were determined on the basis of their performance during a familiarization session. The rates were selected so that over a session there would be some convergence of the "upper rate" and "lower rate" staircases at each arm site if a pain pulse were detected. The "faster" ramp was typically set at $200 \mathrm{msec}$, and the "slower" ramp, at $500 \mathrm{msec}$.

The changes in the rate of ramp-off were under computer control, with the rate-of-change step being doubled if there was not a reversal of subject response within three successive trials. If there was a reversal in responding after only one trial (from detecting a pain pulse to not detecting a pain pulse, or vice versa), the rate-of-change step was halved. At each arm-site the initial step was set at $100 \mathrm{msec}$ for the staircase with the faster ramp time and $200 \mathrm{msec}$ for the staircase with the slower ramp time. The minimum rate-of-change step possible was $10 \mathrm{msec}$; the maximum, $300 \mathrm{msec}$. Ramp-off limits were set at a minimum of $80-\mathrm{msec}$ and a maximum of $2,000-\mathrm{msec}$ duration. These limits were not reached during the experiment. On each trial at the given arm-site, one of the two concurrent staircases was selected at random. The session ended when 30 trials had been completed on 
all four staircases. The nominal limit of 30 trials per staircase ( 60 trials per arm site) was set in order to minimize the possibility of pain stimulus carryover effects influencing subject responding.

\section{RESULTS AND DISCUSSION}

One subject failed to obtain convergence on the staircase procedure. Because this indicates that the subject was using an irrelevant decision making strategy (Cornsweet, 1962), the subject was dropped from any further analysis.

With a sufficiently fast ramp-off rate, all of the remaining subjects $(N=13)$ were able to clearly detect a pain increase at both arm sites. This pulse of pain is consistent with the neural modulation processes that are postulated to occur at the spinal level according to gate control theory. That is, the transient pulse of pain is consistent with a segmental spinal interaction between nociceptive and non-nociceptive inputs, resulting in a decreased inhibition of nociceptive transmission as A-beta activity decreased at the spinal level while C-fiber input transiently remained unchanged.
For each subject, the double random staircases converged rapidly and gave highly consistent data by the last four reversals in responding on each random staircase. Figures 5 and 6 illustrate the difference in detectability of the pain pulse at the upper and lower stimulus sites obtained by the double random staircase method. Rate of ramp-off of $\mathrm{K}^{+}$delivery is plotted against the 30 trials used for each staircase. Figure 5 shows the individual results of two subjects. Figure 6 shows the group average for all 13 subjects.

The results in Figures 5 and 6 are consistent with the prediction of gate control theory-that the production of a pain pulse at a peripheral nociceptive stimulus site closer to the spine would require a greater ramp-off rate in order to produce a detectable pain pulse.

To further analyze the staircase data, the last four response reversals on each staircase were used. For the double random staircase method used, this gave eight data points for each electrode site for each subject. All data analysis is based on these data.
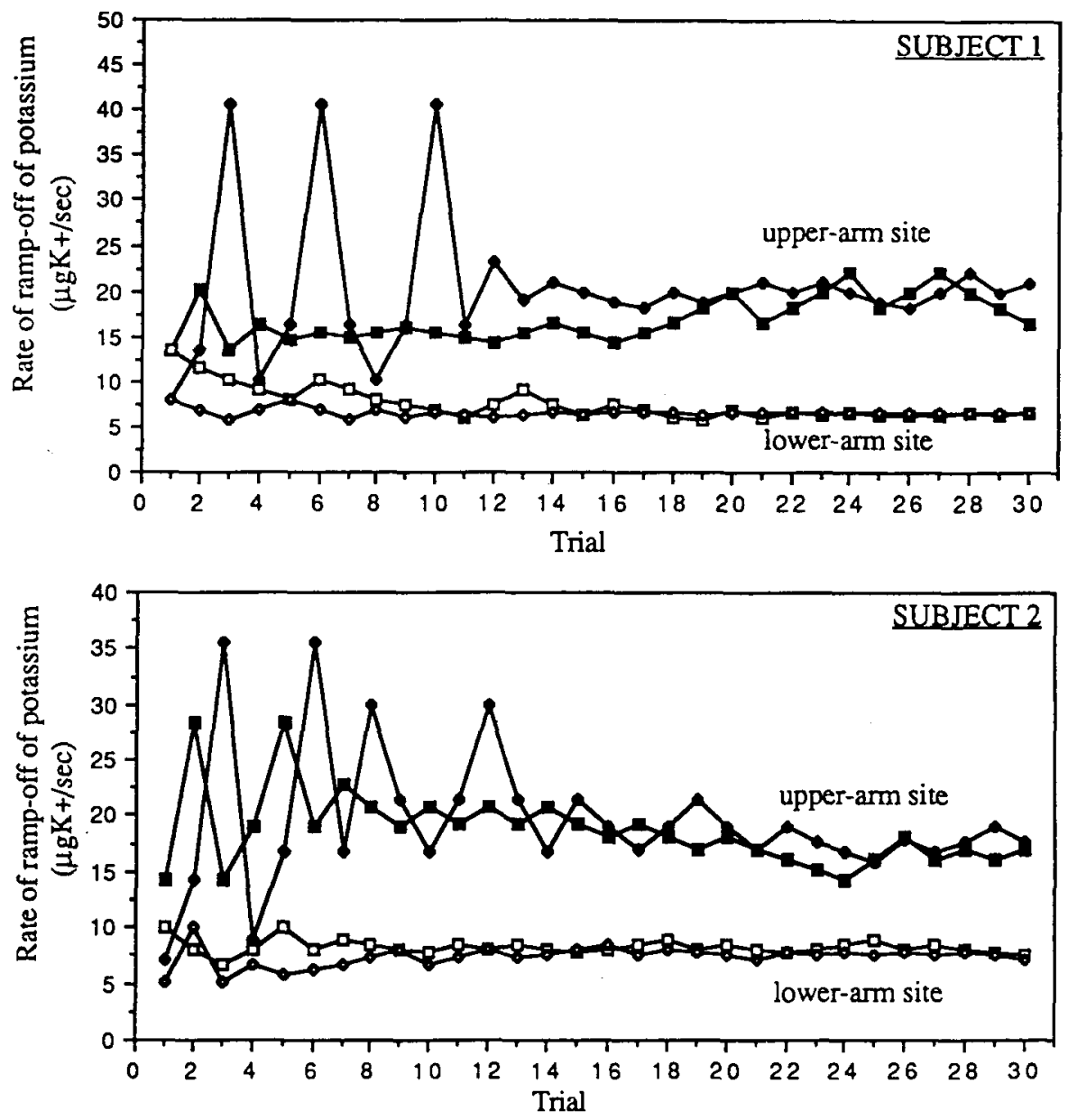

Figure 5. Threshold detection of the pain pulse during the ramping-off of the iontophoretic potassium peripheral pain stimulus. The double random staircase method was used at both the upper and lower arm sites. The rate of ramp-off of the applied $\mathrm{K}^{+}$is plotted against the 30 triais for each staircase. The individual results are for Subject 1 and Subject 2. Filled symbols are for the upper-arm site, open symbols for the lower-arm site. Squares represent the faster initial ramp rate, diamonds represent the slower initial ramp rate. 


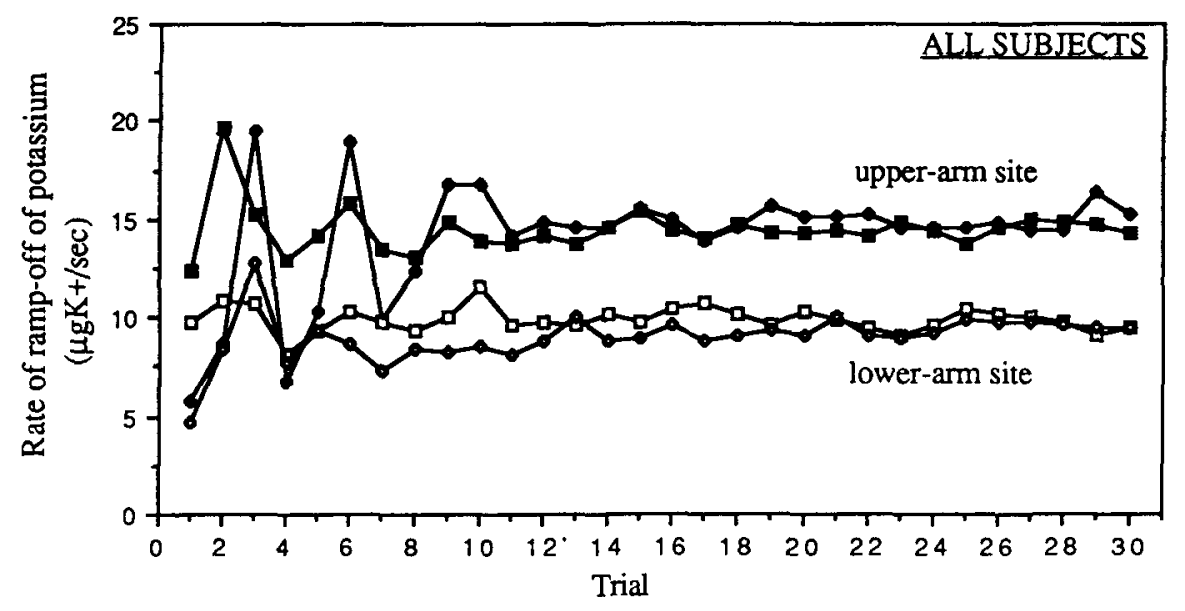

Figure 6. Threshold detection of the pain pulse during the ramping-off of the iontophoretic potassium peripheral pain stimulus. The double random staircase method was used at both the upper- and lower-arm sites. The rate of ramp-off of the applied potassium is plotted against the 30 trials for each staircase. Each data point is the mean value of all subjects $(N=13)$. Filled symbols are for the upper-arm site, open symbols for the lower-arm site. Squares represent the faster initial ramp rate, diamonds represent the slower initial ramp rate.

It was first determined how consistent subject responding was on the two staircases of each double random staircase by comparing the average ramp-off times of each staircase. This comparison provides a quantitative measure of subject response consistency at each arm site, and of whether a sufficient number of trials were run in order to allow the staircases to converge sufficiently. Averaged across all subjects, the difference between the mean value of the two staircases of each double staircase was $22.6 \mathrm{msec}$. If the two staircases in a double staircase are viewed as a replication of the same condition (Cornsweet, 1962), this small difference indicates that sufficient trials were run in order to obtain a consistent measure.

As Figures 5 and 6 show, the potassium iontophoretic nociceptive stimulus was able to provide stable subject responding over repeated trials with minimal drift once the threshold values had been located by the double random staircase method.

The ramp-off time difference, between the reversal point where subjects could not detect a pain pulse and the reversal point where a pain pulse could be detected, averaged over all the individual staircases, was $37.7 \mathrm{msec}$. That is, averaged over all subjects, this change in ramp-off time was sufficient to differentiate the presence or absence of a perceived pain pulse. This small change in ramp time required to locate the pain pulse establishes that the double random staircase method was able to give an accurate measure of pain-pulse threshold. The small change in ramp time also eliminates the possibility that subjects could have used the length of ramp-off time as a response cue. In addition, by self-report at the end of the experiment, all subjects reported that they were indeed attending to the pain pulse as the cue to base their reactions on.

The mean rate of stimulus ramp-off required in order to detect a pain pulse was significantly greater for the upper- arm site $\left[14.3 \mu \mathrm{gK}^{+} / \mathrm{sec}(35.3 \mathrm{~mA} / \mathrm{sec})\right]$ than for the lowerarm site $\left[9.4 \mu \mathrm{gK}^{+} / \mathrm{sec}(23.2 \mathrm{~mA} / \mathrm{sec})\right][t(12)=3.75, p<$ $.01]$; see Table 1 .

A $52 \%$ greater rate of ramp-off of delivered potassium was required at the upper-arm site than of the lower-arm site in order to produce a perceptible pain pulse. The difference in ramp-off rate corresponded to an average rampoff time of 192 and $261 \mathrm{msec}$ for the upper and lower arm sites, respectively.

Averaged over all subjects, the upper-arm site required significantly higher stimulus intensities $\left[2.6 \mu \mathrm{gK}^{+} / \mathrm{sec}\right.$ $(6.3 \mathrm{~mA} / \mathrm{sec})]$ than did the lower-arm site $\left[2.1 \mu \mathrm{gK}^{+} / \mathrm{sec}\right.$ $(5.1 \mathrm{~mA} / \mathrm{sec})][t(12)=3.25, p<.01]$ in order to establish similar constant perceived pain levels before the rampingoff of the stimulus. The different overall level of initial stim-

Table 1

Applied Stimulus Level and the Ramp-Off Rate for the Upper and Lower Arm Sites to Produce Threshold Detection of a Pain Pulse

\begin{tabular}{cccccc}
\hline & \multicolumn{2}{c}{ Stimulus Level } & & \multicolumn{2}{c}{ Ramp-off Rate } \\
\cline { 2 - 3 } \cline { 5 - 6 } Subject & Upper Arm & Lower Arm & & Upper Arm & Lower Arm \\
\hline 1 & 4.1 & 4.1 & & 18.8 & 6.5 \\
2 & 2.8 & 2.0 & & 17.3 & 7.9 \\
3 & 2.4 & 1.2 & & 15.3 & 13.4 \\
4 & 2.0 & 1.2 & & 10.8 & 10.6 \\
5 & 2.0 & 2.0 & & 14.5 & 8.4 \\
6 & 1.6 & 1.2 & & 7.0 & 4.8 \\
7 & 2.4 & 2.4 & & 10.0 & 5.4 \\
8 & 2.8 & 1.6 & & 23.2 & 13.2 \\
9 & 2.4 & 2.0 & & 9.2 & 5.1 \\
10 & 3.2 & 2.0 & & 18.0 & 19.1 \\
11 & 2.4 & 1.6 & & 11.9 & 8.9 \\
12 & 2.8 & 3.2 & & 21.8 & 9.8 \\
13 & 2.0 & 2.0 & & 8.2 & 9.2 \\
Average & 2.6 & 2.1 & 14.3 & 9.4 \\
\hline
\end{tabular}

Note--All values are in $\mu \mathrm{K}^{+} / \mathrm{sec}$. 
ulation at the two arm sites was a possible confound that may have produced the different ramp-off rates required to produce a pain pulse at the different arm sites.

However, for one subgroup of 5 subjects (Subjects 1, 5, 7,12 , and 13 ), the same intensity stimuli were delivered to both sites, or the greater intensity stimulus was delivered to the lower site. For these 5 subjects, the average rate of stimulus ramp-off required in order to detect a pain pulse remained significantly greater for the upper-arm site $\left[14.7 \mu \mathrm{gK}^{+} / \mathrm{sec}(36.2 \mathrm{~mA} / \mathrm{sec})\right]$ than for the lower-arm site $\left[7.9 \mu \mathrm{gK}^{+} / \mathrm{sec}(19.4 \mathrm{~mA} / \mathrm{sec})\right][t(4)=2.73, p<.05]$.

For the remaining 8 subjects, who had a greater initial stimulus level at the upper-arm site, the average rate of stimulus ramp-off required in order to detect a pain pulse was also significantly greater for the upper-arm site $\left[14.1 \mu \mathrm{gK}^{+} / \mathrm{sec}(34.8 \mathrm{~mA} / \mathrm{sec})\right]$ than for the lower-arm site $\left[10.4 \mu \mathrm{gK}^{+} / \mathrm{sec}(25.6 \mathrm{~mA} / \mathrm{sec})\right][t(7)=2.61, p<.05]$.

Thus for both subgroups of subjects, a significantly greater rate of ramp-off of delivered potassium was required at the upper-arm site in order to produce a perceptible pain pulse. Therefore the different levels of initial stimulation at the two arm sites does not provide an explanation for the different ramp-off rates required in order to produce the perceived pain pulse.

In addition, the higher stimulus levels at the upper site would have exposed subjects to a longer ramp-off time for any given rate of ramp-off. This might be expected to give subjects a better opportunity to detect a pain pulse at the upper site, in direct contrast to the prediction of gate control theory - that the pain pulse should be more detectable at the lower arm site.

Other mechanisms, apart from a decrease in A-beta activity at the spinal level, could possibly account for a perceived pain pulse during the ramp-off phase. When a steady current applied to a nerve is suddenly withdrawn, an action potential can be generated in the nerve. This anode break excitation (Douglas \& Ritchie, 1962; Mendell \& Wall, 1964, 1965; Van Den Honert \& Mortimer, 1981) can be avoided by ramping the electrical stimulus off over a period of time, rather than creating a sudden break.

In studies in which anode break excitation has been investigated with the use of applied current levels similar to the present ones, albeit with direct nerve stimulation and current times in the order of milliseconds, anode break excitation has been avoided by using decay constants of 1-30 msec (e.g., Accornero, Bini, Lenzi, \& Manfredi, 1977; Burke \& Ginsborg, 1956; Van Den Honert \& Mortimer, 1981). In the context of the present study, this is equivalent, in terms of overall rate of ramp-off, to stimulus ramp-off times of approximately 3-60 msec. In the present study, a median ramp-off time of $261 \mathrm{msec}$ at the lower-arm site was still able to produce a perceptible pain pulse. This suggests that the pain pulse was not a result of anode break excitation.

A second alternative mechanism that might account for the pulse of pain is that while the potassium ions lead to depolarization of the nerve fibers, any accompanying anodal hyperpolarizing action of the potassium anode might counter that effect (Ranck, 1980, 1981). With the removal of the applied electrical stimulus, the anodal action would disappear while the accumulated potassium could take a brief time to diffuse away so that it would now exert its full depolarizing effects.

Either of these mechanisms which increase A-delta activity might account for any pulse of pain felt during the stimulus ramp-off period. However, peripheral stimulus mechanisms, such as anode break excitation, do not account for why a stimulus site closer to the spine would require a much greater ramp-off rate in order to produce a detectable pain pulse. It cannot be discounted that the perceived pain pulses might have been a function of all three effects: anodal break excitation, anodal hyperpolarization combined with the effects of $\mathrm{K}^{+}$accumulation, and the imbalance of peripheral afferent input as described by gate control theory.

In summary, the results of the present study were generally consistent with the predictions of gate control theory, and none of the data that were obtained directly contradicted the predictions. However, further studies will be required in order to confirm the causal mechanisms that generate the observed pain pulse. Replication of the present study using leg sites, with the advantage of greater distance to the spine, and using different dermatomes as well as potentially using multiple stimulation sites, could provide further support for the ramp-off model.

Microneurographic studies have measured activity in human cutaneous nociceptors (e.g., Adriaensen et al., 1983; Valbo \& Hagbarth, 1968). Ideally, microneurographic experiments are required in order to confirm that the pattern of neural stimulation obtained is that which is assumed by the ramp-off model. In particular, microneurographic studies would be able to discount the possibility that the pain pulses are the result of local action-potential-generating mechanisms such as anode break excitation producing increased activity in A-delta nociceptors during the stimulus ramp-off phase. However, if a combination of mechanisms is operating, measures of neural activity may not easily determine whether the mechanism described by the ramp-off model is a contributory factor in the generation of the pain pulse.

The technique of ramping off a peripheral nociceptive stimulus may be useful for investigating many processes associated with the spinal modulation of pain. For instance, in future studies, one could investigate the extent to which pain pulses can be generated while there are descending controls closing the gate. With factors believed to modulate nociceptive transmission at the spinal level through descending controls, such as some analgesics (see, e.g., Duggan, Hall, \& Headley, 1976; Le Bars \& Besson, 1981), it might be predicted that it would be more difficult to open the pain gate in the presence of such inhibitory descending influences and produce the pain pulse through ramping off a peripheral pain stimulus. That is, the descending controls would be contributing to, and overriding to some extent, the inhibitory influences of A-beta activity. Consequently, under such conditions, the removal of A-beta activity might not be expected to increase as much nociceptive transmission from the first synapses of 
the dorsal horn. Thus, while speculative, it may be possible that the pain pulse generated through the ramping-off of a peripheral nociceptive stimulus may provide a quantitative measure of the extent of descending spinal inhibitory mechanisms.

Price (1988) criticized gate control theory, suggesting that "the tenets of the theory are not so much incorrect as they are currently too general" and that there is a "lack of quantitative specifications concerning the proposed interactions" (p. 221). The present methodology, potentially, provides a quantitative measure of spinal pain modulation.

\section{REFERENCES}

Accornero, N., Bini, G., Lenzi, G. L., \& Manfredi, M. (1977). Selective activation of peripheral nerve fibre groups of different diameter by triangular shaped stimulus pulses. Journal of Physiology, 273, $539-560$.

Adriaensen, H., Gybels, J., Handwerker, H. O., \& Van Hees, J. (1983). Response properties of thin myelinated (A-delta) fibres in human skin nerves. Journal of Neurophysiology, 49, 111-122.

Basbaum, A. I., \& Fields, H. L. (1984). Endogenous pain control systems: Brainstem spinal pathways and endorphin circuitry. Annual Review of Neuroscience, 7, 309-338.

Beitel, R. E., \& Dubner, R. (1976). Response of unmyelinated (C) polymodal nociceptors to thermal stimuli applied to monkey's face. Journal of Neurophysiology, 39, 1160-1175.

Benjamin, F. B., \& HelveY, W. M. (1963). Iontophoresis of potassium for experimental determination of pain endurance in man. Proceedings of the Society for Experimental Biology \& Medicine, 113, 566-568.

Besson, J. M., \& Chaouch, A. (1987). Peripheral and spinal mechanisms of nociception. Physiological Reviews, 67, 67-186.

BEssOU, P., \& PERL, E. R. (1969). Responses of cutaneous sensory units with non-myelinated fibres to noxious stimuli. Journal of Neurophysiology, 32, 1025-1043.

Britton, N. F., Chaplain, M. A. J., \& Skevington, S. M. (1995). A mathematical model for pain: The role of NMDA receptors. Manuscript submitted for publication.

Brown, A. G., \& IGGo, A. A. (1967). A quantitative study of cutaneous receptors and afferent fibres in the cat and the rabbit. Journal of Physiology, 193, 707-733.

Burgess, P. R., \& PerL, E. R. (1973). Cutaneous mechanoreceptors and nociceptors. In A. Iggo (Ed.), Handbook of sensory physiology: Vol. 2 , Somatosensory system (pp. 29-78). Heidelberg: Springer-Verlag.

BURKE, W., \& GinsBorg, B. L. (1956). The electrical properties of the slow muscle fibre membrane. Journal of Physiology, 132, 586-598.

CAmpbell, J. N., \& MEYer, R. A. (1983). Sensitization of unmyelinated nociceptive afferents in monkey varies with skin type. Journal of Neurophysiology, 49, 98-110.

Coderre, T. J., Katz, J., Vaccarino, A., \& Melzack, R. (1993). Contribution of central neuroplasticity to pathological pain: Review of clinical and experimental evidence. Pain, 52, 259-285:

CoRnsweEt, T. N. (1962). The staircase-method in psychophysics. American Journal of Psychology, 75, 485-491.

Dickenson, A. H., Oliveras, J. L., \& Besson, J. M. (1979). Role of the NRM in opiate analgesia as studied by microinjection technique in the rat. Brain Research, 170, 95-111.

Douglas, W. (1994). Does distraction affect various parameters of pain differently? Unpublished master's thesis, Massey University, Palmerston North, New Zealand.

Douglas, W. W., \& Ritchie, J. M. (1962). Mammalian nonmyelinated nerve fibres. Physiological Reviews, 42, 297-334.

Duggan, A. W., Hall, J. G., \& Headley, P. M. (1976). Morphine enkephalin and the substantia gelatinosa. Nature, 264, 456-458.

Fields, H. L. (1990). Primary afferent nociceptors. In H. L. Fields (Ed.), Pain syndromes in neurology (pp. 1-18). London: Butterworths.
Fields, H. L., \& Basbaum, A. I. (1978). Brainstem control of spinal paintransmission neurons. Annual Review of Physiology, 40, 217-248.

Fields, H. L., Heinricher, M. M., \& Mason, P. (1991). Neurotransmitters in nociceptive modulatory circuits. Annual Review of Neuroscience, 14, 219-245.

GarRison, D. W., \& Foreman, R. D. (1994). Decreased activity of spontaneously and noxiously evoked dorsal horn cells during transcutaneous electrical nerve stimulation (TENS). Pain, 58, 309-315.

Gasser, H. S. (1950). Unmedullated fibres originating in the dorsal root ganglia. Journal of General Physiology, 33, 651-690.

GRACELY, R. H. (1988). Multiple-random staircase assessment of thermal pain sensation. In R. Dubner, G. F. Gebhart, \& M R. Bond (Eds.). Proceedings of the Vth World Congress on Pain (pp. 391-394). Amsterdam: Elsevier.

Gracely, R. H., Lota, L., Walter, D. J., \& Dubner, R. (1988). A multiple random staircase method of psychophysical pain assessment. Pain, 32, 55-63.

Guieu, R., TARdy-Gervet, M. F., \& Giraud, P. (1992). Met-enkephalin and beta-endorphin are not involved in the analgesic action of transcutaneous vibratory stimulation. Pain, 48, 83-88.

GuILBAUD, G. (1988). Peripheral and central electrophysiological mechanisms of joint and muscle pain. In R. Dubner, G. F. Gebhart, \& M. R. Bond (Eds.), Proceedings of the Vth World Congress on Pain (pp. 201215). Amsterdam: Elsevier.

Handwerker, H. O., Iggo, A., \& Zimmermann, M. (1975). Segmental and supraspinal actions on dorsal horn neurons responding to noxious and non-noxious skin stimuli. Pain, 1, 147-165.

Humphries, S. A., Johnson, M. H., \& Long, N. R. (1993, August). An investigation of the gate control theory of pain by ramping-off the experimental pain stimulus of potassium iontophoresis. Poster session presented at the VIIth World Congress on Pain, Paris.

HUMPhries, S. A., Long, N. R., \& JohnSON, M. H. (1994). Iontophoretically applied potassium ions as an experimental pain stimulus for investigating pain mechanisms. Perception \& Psychophysics, 56, 637-648.

IGGO, A. (1974). Cutaneous receptors. In J. Hubbard (Ed.), The peripheral nervous system (pp. 347-404). New York: Plenum.

Koltzenburg, M., Kress, M., \& ReEH, P. W. (1992). The nociceptor sensitization by bradykinin does not depend on sympathetic neurons. Neuroscience, 46, 465-473.

Kumazawa, T., \& Mizumura, K. (1977). Thin-fibre receptors responding to mechanical, chemical, and thermal stimulation in the skeletal muscle of the dog. Journal of Physiology, 273, 179-194.

Kumazawa, T., \& PerL, E. R. (1977). Primate cutaneous sensory units with unmyelinated (C) afferent fibres. Journal of Neurophysiology, 40, 1325-1338.

LE Bars, D., \& Besson, J. M. (1981). The spinal site of action of morphine in pain relief: From basic research to clinical applications. Trends of Pharmacological Science, 2, 323-325.

Liebeskind, J. C., \& Paul, L. A. (1977). Psychological and physiological mechanisms of pain. Annual Review of Psychology, 28, 41-60.

LindBlom, U., TAPPER, D. N., \& Wiesenfeld, Z. (1977). The effect of dorsal column stimulation on the nociceptive response of dorsal horn cells and its relevance for pain suppression. Pain, 4, 133-144.

MelzaCK, R., \& WALL, P. D. (1965). Pain mechanisms: A new theory. Science, 150, 971-979.

MElzaCK, R., \& WALL, P. D. (1988). The challenge of pain (2nd ed.). London: Penguin.

MendeLl, L. M. (1966). Physiological properties of the unmyelinated fiber projection to the spinal cord. Experimental Neurology, 16, 316-332.

Mendell, L. M., \& WALL, P. D. (1964). Presynaptic hyperpolarization: A role for fine afferent fibres. Journal of Physiology, 172, 274-294.

Mendell, L. M., \& Wall, P. D. (1965). Responses of single dorsal cord cells to peripheral cutaneous unmyelinated fibres. Nature, 206, 97-99.

MonNIER, M. (1975). Functions of the nervous system: Vol. 3. Sensory functions and perception. New York: Elsevier.

Murphy, A. Z., \& Behbehani, M. M. (1993). Role of norepinephrine in the interaction between the lateral reticular nucleus and the nucleus raphe magnus: An electrophysiological and behavioural study. Pain, 55, 183-193. 
Nathan, P. W. (1976). The gate control theory of pain: A critical review. Brain, 99, 123-158.

Ong, B., Singer, G., \& Wallace, M. (1980). Pain sensations produced by alogens in humans. In C. Peck \& M. Wallace (Eds.), Problems in pain (pp. 101-110). Sydney: Pergamon Press.

PERL, E. R. (1968). Myelinated afferent fibres innervating the primate skin and their response to noxious stimuli. Journal of Physiology, 197, 593-615

Perl, E. R., Kumazawa, T., Lynn, B., \& Kenins, P. (1976). Sensitization of high-threshold receptors with unmyelinated (C) afferent fibres. Progress in Brain Research, 43, 263-276.

Pohl, M., Collin, E., Bourgoin, S., Clot, A. M., Hamon, M., CesSELIN, F., \& LE BARS, D. (1992). In vivo release of calcitonin generelated peptide-like material from the cervicotrigeminal area in the rat. Effects of electrical and noxious stimulations of the muzzle. Neuroscience, 50, 697-706.

PrICE, D. D. (1988). Psychological and neural mechanisms of pain. New York: Raven Press.

Price, D. D., \& Wagman, I. H. (1970). Physiological roles of A and C fibre inputs to the spinal dorsal horn of Macaca mulatta. Experimental Neurology, 29, 383-399.

RANCK, J. B., JR. (1980). Electrical stimulation of neural tissue. In R. F. Rusher (Ed.), Methods in medical research (Vol. 11, pp. 262-269). Chicago: Year Book Medical Publishers.

RaNCK, J. B., JR. (1981). Extracellular stimulation. In M. M. Patterson \& R. P. Kesner (Eds.), Electrical stimulation research techniques (pp. 1-36). New York: Academic Press.

Roberts, W. A., Eaton, S. A., \& Salt, T. E. (1992). Widely distributed GABA-mediated afferent inhibition processes within the ventrobasal thalamus of rat and their possible relevance to pathological pain states and somatotropic plasticity. Experimental Brain Research, 89, 363-372.

Salter, M. W., \& HenRy, J. L. (1986). Differential effects of peripheral vibration on nociceptive versus non-nociceptive neurones in the lumbar dorsal horn of the cat. Neuroscience Abstracts, 12, 736

SALTER, M. W., \& Henry, J. L. (1987). Evidence that adenosine mediates the depression of spinal dorsal horn neurons induced by peripheral vibration in the cat. Neuroscience, 22, 631-650.

Steedman, W. M., Molony, V., \& IgGo, A. (1985). Nociceptive neurons in the superficial dorsal horn of the cat lumber spinal cord and their primary afferent inputs. Experimental Brain Research, 58, 171-182.

TOREBJÖRK, H. E. (1974). Afferent $\mathrm{C}$ units responding to mechanical, thermal and chemical stimuli in human non-glabrous skin. Acta Physiologica Scandinavica, 92, 374-390.

Torebjörk, H. E., \& HaLlin, R. G. (1974). Identification of afferent C units in intact human skin nerves. Brain Research, 67, 387-403.
ToREBJöRK, H. E., \& HALliN, R. G. (1976). Skin receptors supplied by unmyelinated (C) fibres in man. In Y. Zotterman (Ed.), Sensory function of the skin in primates (pp. 475-487). Oxford: Pergamon.

Treede, R.-D., JAHNKE, M. T., \& BromM, B. (1984). Functional properties of $\mathrm{CO}_{2}$ laser activated nociceptive fibres in an intact human skin nerve. In B. Bromm (Ed.), Pain measurement in man: Neurophysiological correlates of pain (pp. 65-78). New York: Elsevier.

TuRSKY, B. (1974). Physical, physiological, and psychosocial factors that effect pain reaction to shock. Psychophysiology, 11, 95-112.

UCHIDA, Y., \& MURAO, S. (1974). Potassium-induced excitation of afferent cardiac sympathetic nerve fibres. American Journal of Physiology, 226, 603-607.

VALBO, A. B., \& HaGBarTH, K. E. (1968). Activity from skin mechanoreceptors recorded percutaneously in awake human subjects. Experimental Neurology, 21, 270-289.

VAN Den HonerT, C., \& Mortimer, J. T. (1981). A technique for collision block of peripheral nerve: Single stimulus analysis. IEEE Transactions of the Biomedicine \& Engineering, 28, 373-378.

VAN HEEs, J. (1976). C fibre input during painful and non-painful skin stimulation with radiant heat. In J. J. Bonica \& D. Albe-Fessard (Eds.), Advances in pain research and therapy (Vol. 1, pp. 35-40). New York: Raven Press.

VAN HeEs, J., \& Gybels, J. M. (1972). Pain related to single afferent C fibres from human skin. Brain Research, 48, 397-400.

VAN HEES, J., \& GYBELS, J. M. (1981). C-nociceptor activity in human nerve during painful and non painful skin stimulation. Journal of Neurology Neurosurgery \& Psychiatry, 44, 600-607.

Voudouris, N. J., Peck, C., \& Coleman, G. (1985). Conditioned placebo responses. Journal of Personality \& Social Psychology, 48, 47-53.

WALL, P. D. (1988). Stability and instability of central pain mechanisms. In R. Dubner, G. F. Gebhart, \& M. R. Bond (Eds.), Proceedings of the Vth World Congress on Pain: Vol. 3. Pain Research and Clinical Management (pp. 13-24). New York: Elsevier.

WILLIS, W. D. (1988). Anatomy and physiology of descending control of nociceptive responses of dorsal horn neurons: Comprehensive review. Progress in Brain Research, 77, 1-29.

Willis, W. D., \& Coggeshall, R. E. (1978). Sensory mechanisms of the spinal cord. New York: Plenum.

Woolf, C. J., \& WALL, P. D. (1982). Chronic peripheral nerve section diminishes the primary afferent A-fibre mediated inhibition of rat dorsal horn neurones. Brain Research, 242, 77-85.

(Manuscript received February 28, 1995; revision accepted for publication October 8,1995 .) 